\title{
RARE FORM OF PRESENTATION IN A HISTIOCYTOMA CASE
}

\author{
Adriana Elena Nica ${ }^{1,3}$, D.N. Paduraru ${ }^{2,3}$, D. Ion ${ }^{2,3}$, Alexandra Bolocan ${ }^{2,3}$, Alexandra Moise ${ }^{3}$, O. Andronic ${ }^{3}$ \\ ${ }^{1}$ Department of Anaesthesiology, Emergency University Hospital Bucharest, Romania \\ ${ }^{2} I I I ' r d$ Department of General Surgery, Emergency University Hospital Bucharest, Romania \\ 3 "Carol Davila" University of Medicine and Pharmacy, Bucharest, Romania
}

\begin{abstract}
Malignant fibrous histiocytoma is also known as malignant fibrous xanthoma and is a form of neoplasm with uncertain histological origin. This tumour is rich in histiocytes and fibroblasts. MFH represent one on the most common type of soft tissue sarcoma but it has a low incidence in general population. We report the case of a 60 years old male patient, presented at the University Emergency Hospital Bucharest for a tumoral mass on the left hemithorax, in evolution for about 1 year, with an accelerated grow in the last 6 months. This case is typically because the patient is a male and he is 60 years old ( range 50-70 years ). In the same time, there are some particularites that make the case special and determin us to draw some conclusions about the management of this pathology. Histiocytoma represent a rare tumoral pathology and it is difficult to do a differential diagnostic preoperatively. Surgery is the cornerstone of treatment for all soft tissues. The goal of surgery is to eradicate disease in the affected area. All excisions of tumoral mass must be with resection margins for oncological security to avoid the possible complications.
\end{abstract}

Keywords: histiocytoma fibrous malignant, xanthoma, thorax

Note: All authors have contributed significantly and have been involved in the writing of the manuscript at draft and any revision stages, and have read and approved the final version.

\section{INTRODUCTION}

Malignant Fibrous Histiocytoma is also known as Malignant Fibrous Xanthoma and it is a malignant neoplasm with uncertain origin. In 1964, this tumor was first described like a specific soft tissue sarcom type by O’Brien and Stout (1).

The frequency of soft tissue sarcomas in general population is down to $1 \%$ of all malignancies and the most common type of these is MFH. (2) It is identified at aproximately $20-30 \%$ of cases. (3)

$\mathrm{MFH}$ is one of the most common type of soft tissue sarcoma. It occurs in adults (range 50-70 years) with a slight male predilection and with a $\mathrm{M}$ : F ratio of $1.2: 1$ (4).

Athough it can affect almost anywhere in the body, it has a predilection for extremities (up to $70 \%$ of patients) (5).

MFH manifests a broad range of histologic appearances with 5 sub-types described (6):

- Storiform-pleomorphic - is the most common type of sarcoma in patients older than
40 years, accounting for up to $70 \%$ of most cases;

- Myxoid - is the second most common, accounting for approximately $20 \%$ of cases;

- Giant cell - is a rare form;

- Inflammatory - tends to occur in retroperitoneum;

- Angiomatoid - usually occurs in young adults/adolescents.

The most common clinical presentation is as an enlarging painless soft-tissue mass, typically 5-10 $\mathrm{cm}$ diameter. Symtoms such as weight loss and fatigue are not typical but can be present at patients with advanced disease. Frequent, the biological status of pacient is not affected. For paraclinical diagnostic, we can use ultrasonography of soft tissues, CT, IRM (7). An incisional biopsy or an excisional biopsy with a histopathologic evaluation on the tissue, is the method that provides the certain diagnostic.

Macroscopically, the tumor is typically large, well circumscribed but unencapsulated with a grey 
firm heterogeneous cut surface, sometimes with areas of hemorrhage and necrosis.

Microscopically, it is a heterogeneous fibroblastic tumor made up of poorly differenteated fibroblasts, myofibroblasts, histiocyte-like cells with storiform arhitecture and also demonstrate bizarre multi-nucleated giant cells with atipicaly mitosis.

Immunohistochemistry has a little value in the diagnosis of the MFH because the lesion hasn't any specific marker $(6,8)$.

The prognostic depends on the following factors: tumour size, location (superficial is better), histological grade and the presence/absence of metastases.

The survival at 10 years is $90 \%$ in noncomplicated forms and in aggresiv forms of MFH is only $20 \%$. Regional lymph node involvement occurs in $0-15 \%$ of cases and distant metastases are found in $25-35 \%$ of cases. Local recurrence is present in 20 $41 \%$ of cases $(5,9,10)$.

\section{CASE PRESENTATION}

We present the case of a 60 -year old male patient who came to the doctor because of a lump that had appeared on his left hemithorax about 1 year before. During the last 6 months prior to the presentation the lump started growing in an accelerated manner. Previous medical history and family history did not bring any relevant information regarding the incriminated pathology.

Clinical examination reveals a tumor-like formation on the left hemithorax with a diameter of about $10 \mathrm{~cm}$, soft, motionless in relation to the underlying tissues, painless when palpated and having an intense erythematous area on the skin overlying the tumor (Fig. 1,2,3).

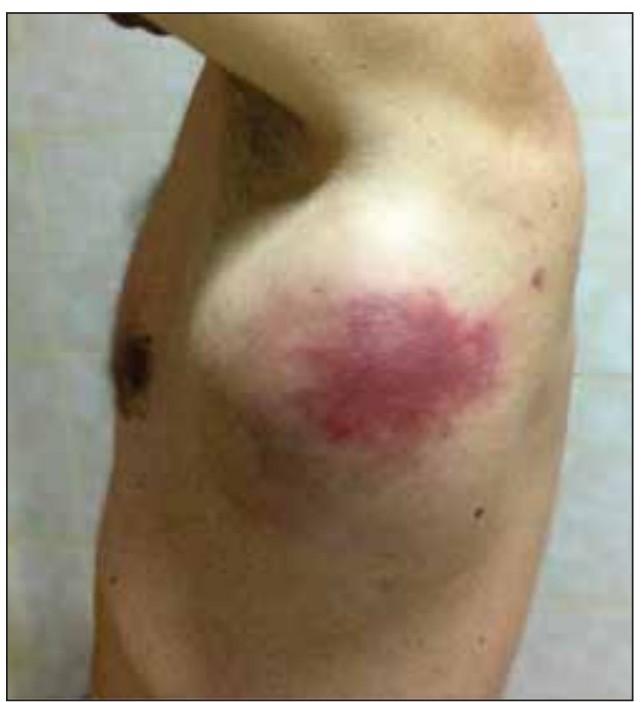

FIGURE 1. Tumor-like formation - lateral view

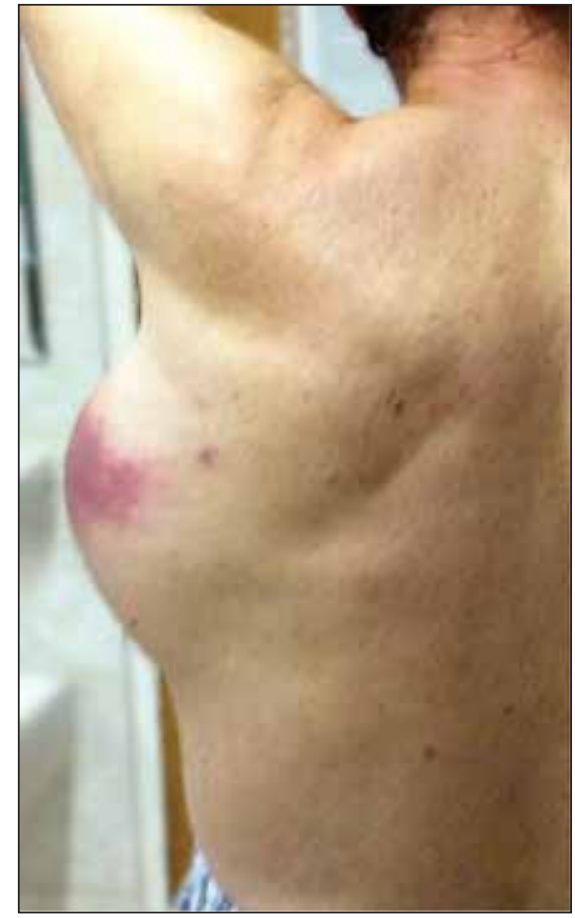

FIGURE 2. Tumor-like formation - posterior view

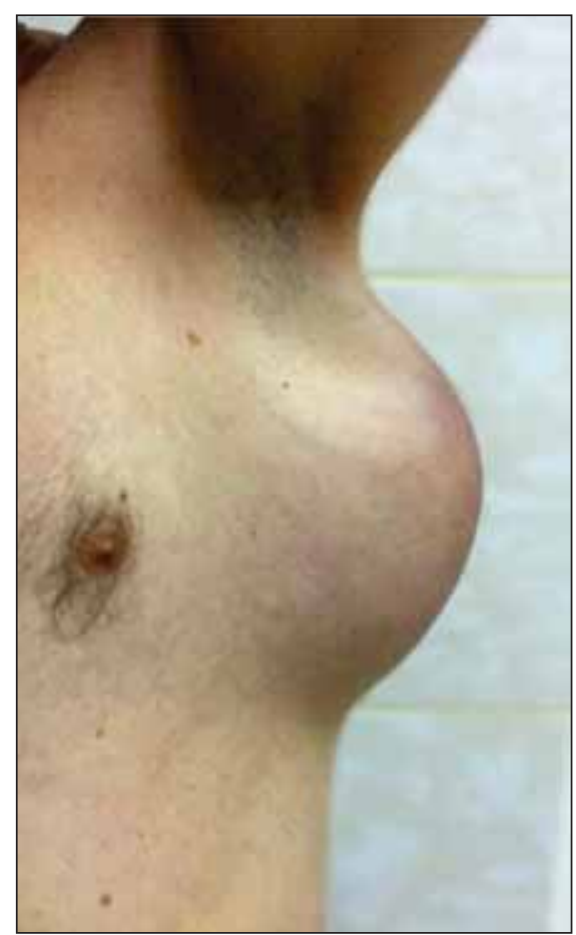

FIGURE 3. Tumor-like formation - anterior view

The complete biological exam shows a minimal inflammatory syndrome $-\mathrm{VSH}=13 \mathrm{~mm} / 1 \mathrm{~h}(\mathrm{~N}$ : $3-10 \mathrm{~mm})$, Fibrinogen $=460 \mathrm{mg} / \mathrm{dL}(\mathrm{N}: 200-400$ $\mathrm{mg} / \mathrm{dL}$ ) without any other pathological changes regarding the blood count, biochemistry and coagulogram.

Imaging examination - ultrasound revealed a subcutaneous soft tissue formation with a hypoechogenyc ultrasound signal, with an inhomogeneous structure and measuring $14 / 11 / 9 \mathrm{~cm}$. The 
Doppler exam revealed a present intratumoral signal, which indicates the presence of vascularization inside the tumor.

The surgical intervention was then decided and performed with the purpose of tumor excision under general anesthesia with endotracheal intubation. The dissection of the tumor with an oncological safety border was performed intraoperative, along with a rigorous hemostasis. The resection piece was sent to be examined histopathologically. Samples of adjacent tissue were also excised in order to confirm the lack of invasion. In their case the histopathological exam did not identify any tumor cells (Fig. 4).

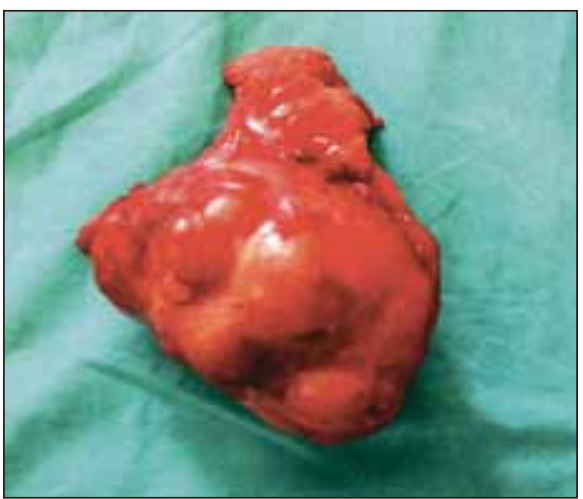

FIGURE 4. Resection piece - macroscopic aspect

The histopathological exam showed an encapsulated tumor-like formation, having $15 / 11 / 8 \mathrm{~cm}$ in dimensions, with a polycyclic contour and a smooth outer surface. When sectioned the surface presented a relatively homogenous aspect, white/grey/ pink, with a multinodular character and high in consistency. The final diagnostic was: pleomorphic malign fibrous histiocytoma (Fig. 5, 6).

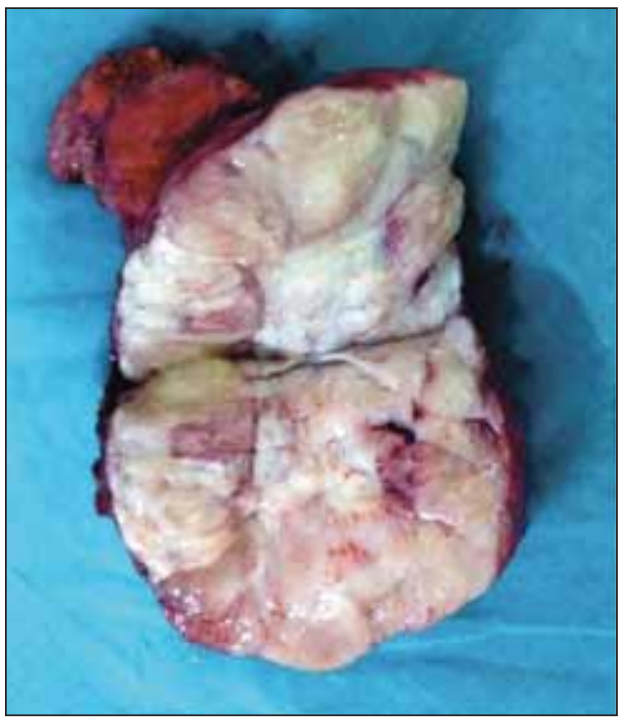

FIGURE 5. Tumor-like formation - macroscopic aspect - sagital section

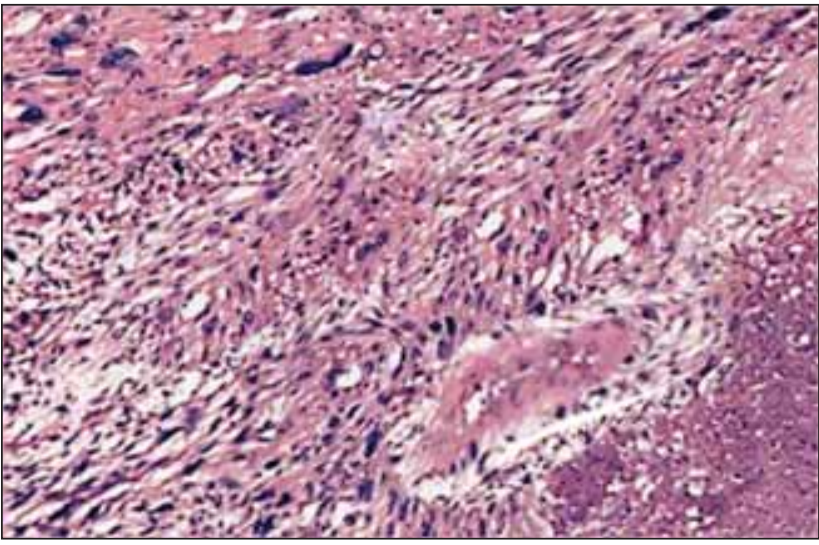

FIGURE 6. Resection piece-Microscopic aspecttumor proliferation which consists of cells with an intense nuclear pleomorphism with a storiform and fascicular pattern

The postoperative evolution was favorable, the patient being released as surgically cured. The next follow-ups after 6 months, 1 year and 3 years did not detect any local relapses or other complications.

\section{DISSCUTIONS}

This case is typically because the patient is a male and he is 60 years old (range 50-70 years ). In the same time, there are some particularites that make the case special and determin us to draw some conclusions about the management of this pathology.

Most cases of malignant fibrous histiocytoma under literare cited prezent a slow growth of the tumor mass for more then 2 years and they rarely arrived at up to $10 \mathrm{~cm}$ diameter. This patient prezents a fast growth of the mass for about 1 year, with an accelerated grow in the last 6 months. These aspects did the presentation in our service to be late., the tumor size was $15 \mathrm{~cm}$.

Frequent, this histological type-pleomorphic has a predilection for extremities -up to $70 \%$ of cases.

The location of this malignant fibrous histiocytoma on the thorax is extremely rare and it is very difficult to do a differential diagnostic preoperatively. In many situations this tumor location is a local complication of rediotherapy for other types of cancer. Our pacient has no history of other disease.

Location and big dimensions of the tumor mass were the reasons which determine the surgeon to excision with resection margins for oncological security without an anterior needlebiopsy. The differential diagnostic of this pathology includes benign tumors, we must know that there is a big probability to be a malignant neoplasm. 
The excision of any mass tumor for which we do not have a certain diagnostic we should think of a maliganant tumor. The goal surgery is to remove all tumor with negative margins.

In literature, up to $50 \%$ of MFH present an aggressive biological behavior and poor prognosis with local recurrence of the tumor and metastases in the next 2 years postop. In our patient situation the evolution was good without any complication for 3 years postop.

\section{CONCLUSIONS}

Hystiocitoma represent a rare pathology for a general surgeon.

\section{REFERENCES}

1. OBrien J.E., Stout A.P. Malignant fibrous xanthomas. Cancer 1964; 17: $1445-1455$

2. Salo J.C., Lewis J.J., Woodruff J.M. Malignant fibrous histiocytoma of the extremity. Cancer. 1999; 85:1765-72.

3. Enzinger F.M., Weiss S.W. Soft tissue tumors. 3rd ed. St. Louis: Mosby; 1995

4. Belal A., Kandil A., Allam A., Khafaga Y., El-Husseiny G., El-Enbaby A., Memon M., Younge D., Moreau P., Gray A., Schultz H. Malignant fibrous histiocytoma: a retrospective study of 109 cases. Am J Clin Oncol. 2002 Feb; 25(1):16-22.

5. Weiss S.W., Enzinger F.M. Malignant fibrous histiocytoma: an analysis of 200 cases. Cancer. 1978 Jun; 41(6):2250-66. PubMed PMID: 207408

6. Enzinger F.M., Lattes R., Torloni H. Histological typing of soft tissue tumours. In International Histological Classification of Tumours, no. 3. Geneva, World Health Organization. 1969.

7. Gladish G.W., Sabloff B.M., Munden R.F., Truong M.T., Erasmus J.J., Chasen M.H. Primary thoracic sarcomas. Radiographics 2002; 22:621-637.

8. Soule E.H., Enriquez P. (1972), Atypical fibrous histiocytoma, malignant fibrous histiocytoma, malignant histiocytoma, and epithelioid sarcoma. A comparative study of 65 tumors. Cancer, 30: 128-143. doi: 10.1002/1097-0142(197207)30:1<128:: AID-CNCR2820300119>3.0.CO;2-W

9. Berkson J., Gage R.P. Calculation of survival rates for cancer. Proc. Staff Meet. Mayo Clin. 25: 270-286, 1950.
The location of this malignant fibrous histiocytoma on the thorax is extremely rare and it is very difficult to do a differential diagnostic preoperatively.

The goal of surgery is to eradicate disease in the affected area. All excisions of tumoral mass must be with resection margins for oncological security to avoid the possible complications.

Immunohistochemistry has a little value in the diagnosis of malignant fibrous histiocytoma because the lesion has not any specific marker.

10. Rosas-Uribe A., Ring A.M., Rappaport H. Metastasizing retroperitoneal fibroxanthoma (malignant fibroxanthoma). Cancer 26: 827-831, 1970.

11. Liu C., Zhao Z., Zhang Q., Wu Y., Jin F. Primary malignant fibrous histiocytoma of the breast: report of one case. Onco Targets and therapy. 2013; 6:315-319. doi:10.2147/OTT.S42022.

12. Souba W.W., McKenna R.J., Meis J., Benjamin R., Raymond A.K., Mountain, C.F. (1986), Radiation-induced sarcomas of the chest wall. Cancer, 57: 610-615. doi: 10.1002/1097-0142(19860201)57: 3<610:: AID-CNCR2820570336>3.0.CO;2-P

13. An J.K., Oh K.K. Malignant Fibrous Histiocytoma of Chest Wall. Yonsei Medical Journal. 2005; 46(1):177-180. doi:10.3349/ ymj.2005.46.1.177.

14. Belal A., Kandil A., Allam A., Khafaga Y., El-Husseiny G., El-Enbaby A., et al. Malignant fibrous histiocytoma: a retrospective study of 109 cases. Am J Clin Oncol. 2002; 25:16-22.

15. Balaji S.M. Malignant Fibrous Histiocytoma - Case Report. Journal of Maxillofacial \& Oral Surgery. 2010; 9(3):292-296. doi:10.1007/ s12663-010-0067-y.

16. Akbulut S., Arikanoglu Z., Basbug M. Benign fibrous histiocytoma arising from the right shoulder: Is immunohistochemical staining always required for a definitive diagnosis? International Journal of Surgery Case Reports. 2012; 3(7):287-289. doi:10.1016/j. ijscr.2012.03.006. 